\title{
Differences in Extracellular Matrix Composition and its Role in Invasion in Primary and Secondary Intracerebral Malignancies
}

\author{
JÓZSEF VIRGA ${ }^{1 *}$, CSABA DÁVID SZEMCSÁK $^{1 *}$, JUDIT REMÉNYI-PUSKÁR $^{1}$, \\ JUDIT TÓTH ${ }^{2}$, TIBOR HORTOBÁGYI ${ }^{3}$, ÉVA CSŐSZ ${ }^{4}$, GÁBOR ZAHUCZKY ${ }^{5}$, \\ LÁSZLÓ SZIVOS ${ }^{1}$, LÁSZLO BOGNÁR $^{1 *}$ and ALMOS KLEKNER ${ }^{1 *}$ \\ ${ }^{1}$ Department of Neurosurgery, Clinical Centre, University of Debrecen, Debrecen, Hungary; \\ ${ }^{2}$ Department of Oncology, Clinical Centre, University of Debrecen, Debrecen, Hungary; \\ ${ }^{3}$ Department of Neuropathology, Institute of Pathology, \\ MTA-DE Cerebrovascular and Neurodegenerative Research Group, University of Debrecen, Debrecen, Hungary; \\ ${ }^{4}$ Proteomics Core Facility, Department of Biochemistry and Molecular Biology, \\ Faculty of Medicine, University of Debrecen, Debrecen, Hungary; \\ ${ }^{5}$ UD-GenoMed Medical Genomic Technologies Research \& Development Services Ltd., Debrecen, Hungary
}

\begin{abstract}
Background/Aim: The most common malignant primary brain tumor is glioblastoma which infiltrates the peritumoral brain, while secondary brain metastases are well demarcated malignancies. Previous research has proved the pivotal role of the changes in the extracellular matrix (ECM) in cancer cell invasion. Materials and Methods: The mRNA expression of 40 ECM molecules was determined using $q R T$ $P C R$ in 54 fresh-frozen glioblastoma and brain metastasis samples. Seventy-two samples were used to determine the levels of 20 ECM proteins. Results: The mRNA and protein expression pattern of the studied tumors differs greatly. Linear discriminant analysis of mRNA expression identified samples based on their $m R N A$ expression profile with $92.3 \%$ probability and highlighted the role of some molecules as their level greatly influenced sample identification. Conclusion: Different tumor types with different invasiveness differ in the composition of their ECM and this can be used to identify samples. Furthermore, some ECM molecules greatly contribute to tumor invasiveness and could be targets of anti-invasive oncotherapy.
\end{abstract}

Intracranial malignant tumors can be classified as primary and secondary (i.e. metastatic) tumors. Primary brain tumors

*These Authors contributed equally to this study.

Correspondence to: Dr. Almos Klekner, Department of Neurosurgery, University of Debrecen, Clinical Centre, 4032 Nagyerdei Krt. 98. Debrecen, Hungary. Tel/Fax: +36 52419418, email: neurosurgery.debrecen@freemail.hu

Key Words: Glioblastoma, brain metastasis, invasion, extracellular matrix, expression. have an incidence rate of 7.18 over 100,000 . The most common type of malignant primary brain cancer is glioblastoma (GBM) $(1,2)$. The prognosis of the disease is poor, as cancer cells are rather resistant to chemotherapy and irradiation. Furthermore, complete surgical resection is not possible due to the high degree of peritumoral infiltration which leads to tumor recurrence $(3,4)$. Brain metastases develop in $7-15 \%$ of cancer patients however, it is assumed that the actual rate is higher. The most common sources are lung cancer, breast cancer and melanoma. Patient outcome is mostly dependent on the primary disease (5).

During malignant transformation, cancer cells develop the ability to invade their surroundings, blood and lymphatic vessels. The infiltration takes place as a result of a complex multistep process in which the components of the extracellular matrix (ECM) play an important role. It has been previously described that various ECM components are expressed differently in tumor tissue compared to normal brain (6-10). Primary and secondary brain cancer not only differ in their origin but also in their invasiveness. Brain metastases are well demarcated lesions which, despite being able to invade blood and lymphatic vessels, do not infiltrate the peritumoral brain $(11,12)$. On the other hand, glioma cells invade the neighboring brain tissue, there is no sharp border of the tumor and tumors cells migrate centimeters away from the tumor mass. However, distant metastases in glioblastoma, are extremely rare $(3,11)$. The surgical resection is a much less challenging procedure in cases of metastatic tumors compared with those of glioblastomas $(4,12)$.

In order to gain more understanding of which ECM components are more involved in the invasion of the peritumoral brain, the expression levels of cell-surface receptors and their ligands, as well as synthetizing and degrading 
enzymes of the ECM were measured in glioblastoma, non-small cell lung cancer and non-tumor brain tissue samples.

\section{Materials and Methods}

Tissue samples. Tumor samples were taken from patients operated at the University of Debrecen Department of Neurosurgery. An informed consent form was signed by each patient and the research was approved by the National Research Ethics Committee. Samples were frozen intraoperatively on the surface of liquid nitrogen and stored at $-80^{\circ} \mathrm{C}$ until further use. The samples were first evaluated by a neuropathologist for confirming the diagnosis and the amount of tumor tissue in the sample, and the remaining pieces of tissue were used for RNA isolation and protein analysis. The ECM components were selected after an extensive literature review, as well as based upon previous findings from our research group (Table I) $(7,9,13-15)$.

mRNA expression measurements. The mRNA expression level of 40 molecules was determined through real-time quantitative reverse transcriptase-polymerase chain reaction (qRT-PCR) in 27 normal brain tissue samples, 10 metastatic tumor tissue samples, and 17 glioblastoma samples. Freshly frozen tissue samples were first pulverized and then homogenized using TriReagent ${ }^{\circledR}$ (Invitrogen, MA, USA). Total RNA was isolated from TriReagent lysates according to the manufacturer's instructions. A NanoDrop ${ }^{\circledR}$ ND-1000 Spectrophotometer (NanoDrop Technologies, DE, USA) was used to measure the quantity and purity of the RNA, after which reverse transcription was performed to convert total RNA to single-stranded cDNA with the help of a High-Capacity cDNA Archive Kit with RNasin (Applied Biosystems, CA, USA). The cDNA was then loaded onto a microfluidic card (cDNA from 100ng of total RNA per port). An Applied Biosystems 7900HT Real-Time PCR System with a Micro Fluidic Card upgrade (Applied Biosystems, CA, USA) was used to perform TaqMan low-density array (TLDA) experiments. The micro fluidic cards were analyzed with SDS 2.1 software for relative quantification studies, and the cycle threshold (CT) values were exported for further analysis. The $\beta$-actin and glyceraldehyde 3-phosphate dehydrogenase (GAPDH) housekeeping genes exhibited the fewest variations among the samples and GAPDH was used as reference gene to calculate the $\mathrm{dCt}$ value for each gene. Expression values were calculated using the comparative CT method, as described previously (16).

Protein expression measurements. After determining the levels of mRNA present in the samples, a mass spectrometer was used to measure concentrations of the transcribed proteins in 20 of the molecules (Table I, bold) to uncover expressional changes using 36 normal tissue samples, 12 metastatic tumor samples, and 24 glioblastoma samples. Tissue homogenization for protein analysis was performed as described in the case of RNA purification; however, a lysis buffer containing $50 \mathrm{mM}$ Tris, $1 \mathrm{mM}$ EDTA, $17 \mathrm{mM}$ betamercaptoethanol, and $0.5 \%$ Triton-X100 ${ }^{\mathrm{TM}}$ was used in this case for tissue lysis. The protein content was measured using the Bradford method, and equal amounts of proteins were used for in-solution trypsin digestion (17). The selected reaction monitoring (SRM)-based targeted proteomic method was developed for relative protein amount determination $(18,19)$. For protein concentration estimation, the area under the curve of the acquired spectra was calculated; SRM spectra were used for AUC calculations if the intensity of the signal exceeded 500 cps. Data integration based on the curve shape determined from pilot analyses was completed with the help of Analyst 1.4.2 software.
Table I. Invasion-related molecules of the extracellular matrix selected for analysis. Forty components were selected for mRNA analysis, 20 of which were confirmed by protein expression analysis (molecules in bold).

\begin{tabular}{ll}
\hline Cell-surface receptors & Cell-surface receptor ligands \\
\hline CD44 & Agrin \\
EGFR (ErbB1) & Brevican \\
ErbB2 & Cadherin-N \\
ErbB4 & Cadherin-N2 \\
Integrin alpha1 & Cadherin-P \\
Integrin alpha3 & Collagen type I alpha1 \\
Integrin alpha5 & Collagen type III alpha1 \\
Integrin alpha7 & Collagen type IV alpha1 \\
Integrin alpha9 & Collagen type VIII alpha1 \\
Integrin alpha11 & Fibronectin \\
Integrin beta1 & Laminin alpha4 \\
Integrin beta3 & Laminin beta1 \\
HMMR (CD168) & Laminin beta2 \\
& Matrilin-2 \\
& Neurocan \\
& Neuroglycan C \\
& Perlecan \\
& Syndecan-1 \\
& Syndecan-3 \\
& Syndecan-4 \\
& Tenascin-C \\
& Tenascin-R \\
& Versican \\
& \\
\hline
\end{tabular}

Enzymes in the ECM

Hyaluronan synthase-1

Hyaluronan synthase-2

Matrix metalloproteinase-2

Matrix metalloproteinase-9

Statistical analysis. During statistical analysis, the differences between the expression levels of individual genes were determined using one-way ANOVA. A result of $p \leq 0.05$ was considered significant. Linear discriminant analysis (LDA) was used to identify key molecules that were playing a crucial role in the development of the invasive character of the tumors. Furthermore, with the LDA of the typical expression pattern of each histopathological group, the invasion spectrum could also be established. To confirm the connection between the invasion spectrum and tumor type, the origins of unknown samples were identified using Bayes network and LogitBoost methods.

\section{Results}

The mRNA and protein expression patterns of invasionrelated molecules in brain metastases, primary brain tumors, and non-tumorous brain tissue differ greatly. During the analysis of the results, the expression of the ECM molecules were found to be significantly different in the three studied groups. Average expression levels can be seen on Figure 1. 


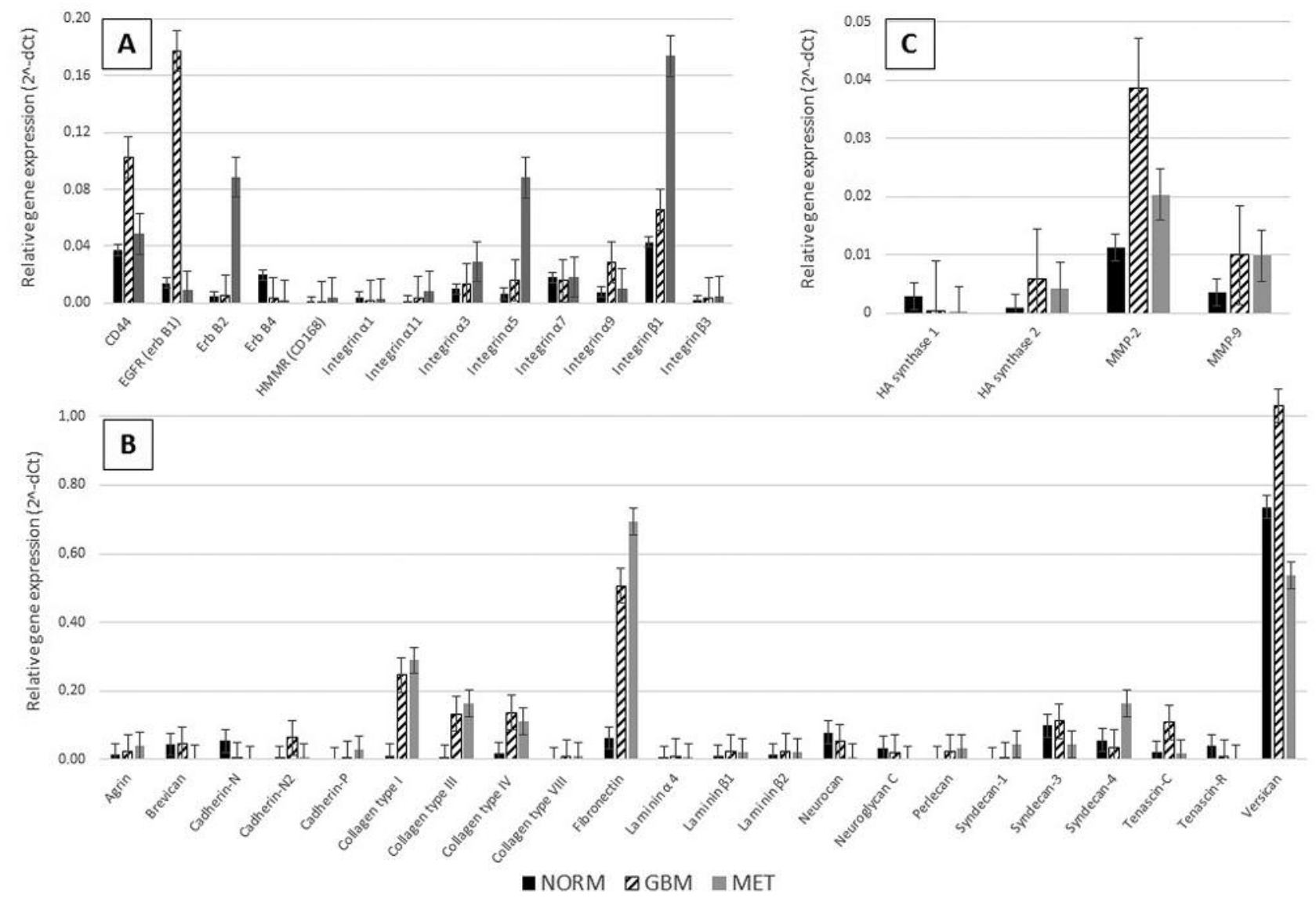

Figure 1. Average mRNA expression of various ECM components in normal brain, glioblastoma and NSCLC brain metastasis. A: Cell-surface receptors; $B$ : ligand components in the ECM; C: enzymes in the ECM.

Normal tumor samples differed from GBM samples in a high number of ECM components. Significant difference was observed in the expression of $C D 44$, cadherin- $N$, cadherin$N 2$, collagen type I $\alpha 1$, - type III $\alpha 1$, - type IV $\alpha 1$, - type VI $\alpha 1, E G F R$, ErbB4, fibronectin, hyaluronan synthase-1, -2, $H M M R(C D 168)$, integrin- $\alpha 9,-\beta 1,-\beta 3$, laminin- $\alpha 4,-\beta 1,-$ $\beta 2$, matrix metalloproteinase $-2,-9$, perlecan, tenascin- $C$ and $-R$. Normal and metastatic tumor samples also showed great differences. The average expression of agrin, brevican, cadherin- $N$, cadherin- $P$, collagen type I $\alpha 1$, - type III $\alpha 1$, type IV $\alpha 1$, - type VI $\alpha 1$, ErbB4, fibronectin, hyaluronan synthase-1, HMMR (CD168), integrin- $\alpha 5,-\alpha 11,-\beta 1,-\beta 3$, laminin- $\beta 2$, matrillin- 2 , neurocan, neuroglycan- $C$, perlecan, syndecan-1, -4 , and tenascin- $R$ was significantly different between these groups. Not only tumor and non-tumor samples showed significant differences (as it can be read above, a total of 14 ECM components were expressed differently in both tumor groups compared to normal brain) but primary and secondary malignancies also have differences. Agrin, brevican, CD44, cadherin-N2, cadherin$P, E G F R$, integrin- $\alpha 5, \alpha-9, \alpha-11$, matrillin-1, matrix metalloproteinase-9, neurocan, neuroglycan-C, syndecan- 1 , $-3,-4$, and tenascin- $C$ mRNA expression showed significant differences between GBM and metastatic samples.

Protein expression analysis also revealed significant differences in the invasion spectrum of the studied groups of samples. Differences in the average protein expression can be seen in Figure 2. Normal brain tissue and GBM samples showed significant differences in the cases of EGFR, ErbB2, integrin- $\beta 1$, laminin- $\alpha 4,-\beta 1$, matrix metalloproteinase -2 and -9 . Metastatic tumor tissues differed significantly from non-tumor brain only in the case of integrin- $\alpha 7$ out of the 20 analyzed ECM components. Primary and secondary brain tumors, on the other hand, proved to be significantly different in the levels of integrin- $\alpha 7,-\beta 1$, matrixmetalloproteinase-9 and neurocan.

mRNA and protein expression of ECM components in various samples often show concordant changes. When analyzing the expression levels of various ECM components, it was seen that mRNA and protein expression often but not always follows the same direction 


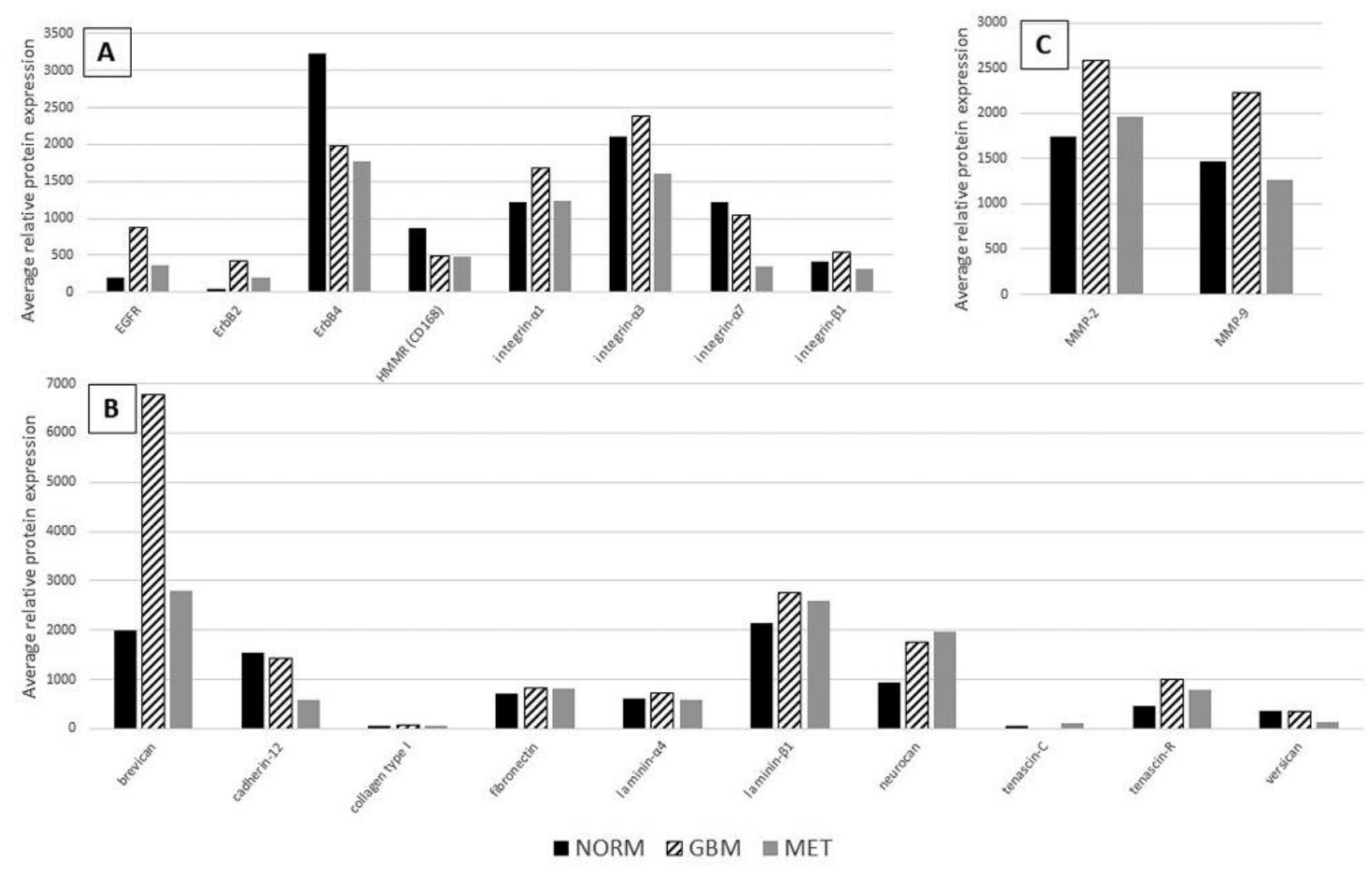

Figure 2. Average protein expression of various ECM components in normal brain, glioblastoma and NSCLC brain metastasis. A: Cell-surface receptors; $B$ : ligand components in the ECM; C: enzymes in the ECM.

in tumor samples compared to normal brain. Table II summarizes these changes in expression. Concordant changes were observable most often in the expressional differences between normal brain and GBM. There were 13 ECM components showing concordant changes in mRNA and protein expression, 4 of which were found significant both on mRNA and protein level (Figure 3A). ErbB2 was the only molecule that showed concordant expression but was significant only on protein level, all the other 12 were significant on mRNA level. The comparison of NSCLC metastasis and normal brain tissue revealed concordant alterations in 7 cases (Figure 3B). ErbB2, ErbB4, neurocan and tenascin- $R$ were significant on mRNA level, the other 3 ECM component showed concordant, but non-significant changes in expression, this however, may be due to the smaller sample number. Primary and secondary brain tumors showed concordant changes in the expression of ECM components in 6 components (Figure 3C). Neurocan expression showed significant and concordant changes both on mRNA and protein level, cadherin-N2 and EGFR were significant on
mRNA level only, while matrix metalloproteinase-9 was significant on protein level only. ErbB4 and laminin- $\alpha 4$ were not significant but concordant only.

Linear discriminant analysis of the results revealed key ECM molecules that play a prominent role in the invasive character of various tumor types, while the expression pattern is characteristic of each histological group. During a further examination of the results, key molecules were identified by linear discriminant analysis (LDA), which helps in the differentiation of the various histological groups. The LDA identified the following key RNA molecules: cadherin- $N$, collagen type IV $\alpha 1$, Erb-B2, hyaluronan synthase-2, integrin- $\alpha 3,-\alpha 5$, and $-\alpha 9, M M P-9$, and syndecan-1. Following cross-validation, a sample of unknown origin was identified with a $92.3 \%$ probability during LDA. The Bayes network model was also used to identify the origin of an unknown sample; this method correctly identified $92.6 \%$ of the samples.

The most accurate results were achieved with the LogitBoost method to identify unknown samples based on 
Table II. Invasion-related ECM components that show concordant changes in $m R N A$ and protein expression.

\begin{tabular}{|c|c|c|c|}
\hline Molecule & $\begin{array}{l}\text { Compared } \\
\text { groups }\end{array}$ & $\begin{array}{l}\text { Direction } \\
\text { of change }\end{array}$ & $\begin{array}{l}\text { Level of } \\
\text { significance }\end{array}$ \\
\hline brevican & $\begin{array}{c}\text { norm. vs. GBM } \\
\text { GBM vs. met }\end{array}$ & $\begin{array}{l}\uparrow \\
\downarrow\end{array}$ & $\begin{array}{l}\text { not significant } \\
\text { mRNA: ** }\end{array}$ \\
\hline $\begin{array}{l}\text { cadherin-N2 } \\
\text { collagen type I }\end{array}$ & $\begin{array}{l}\text { GBM vs. met. } \\
\text { norm vs. GBM }\end{array}$ & $\uparrow$ & $\begin{array}{l}\text { mRNA: } * * * * \\
\text { mRNA: } *\end{array}$ \\
\hline EGFR & $\begin{array}{l}\text { norm. vs. GBM } \\
\text { GBM vs. met. }\end{array}$ & $\uparrow$ & $\begin{array}{c}\text { mRNA: }{ }^{*} \text {, protein: } * * * \\
\text { mRNA: } *\end{array}$ \\
\hline Erb B2 & $\begin{array}{c}\text { norm. vs. GBM } \\
\text { norm. vs. met }\end{array}$ & $\begin{array}{l}\uparrow \\
\uparrow\end{array}$ & $\begin{array}{c}\text { protein: } * * * \\
\text { not significant }\end{array}$ \\
\hline Erb B4 & $\begin{array}{c}\text { norm. vs. GBM } \\
\text { norm. vs. met } \\
\text { GBM vs. met. }\end{array}$ & $\begin{array}{l}\downarrow \\
\downarrow \\
\downarrow\end{array}$ & $\begin{array}{l}\text { mRNA: } * * * * \\
\text { mRNA: } * * * * \\
\text { not significant }\end{array}$ \\
\hline integrin alpha-3 & norm. vs. GBM & $\uparrow$ & not significant \\
\hline integrin beta-1 & norm. vs. GBM & $\uparrow$ & mRNA: $* * *$, protein: $* *$ \\
\hline laminin alpha-4 & $\begin{array}{l}\text { norm. vs. GBM } \\
\text { norm. vs. met. } \\
\text { GBM vs. met. }\end{array}$ & $\begin{array}{l}\uparrow \\
\uparrow \\
\downarrow\end{array}$ & $\begin{array}{c}\text { mRNA: } * *, \text { protein: } * \\
\text { not significant } \\
\text { not significant }\end{array}$ \\
\hline laminin beta-1 & $\begin{array}{c}\text { norm. vs. GBM } \\
\text { norm. vs. met. }\end{array}$ & $\begin{array}{l}\uparrow \\
\uparrow\end{array}$ & $\begin{array}{c}\text { mRNA: }{ }^{*}, \text { protein: } * \\
\text { not significant }\end{array}$ \\
\hline MMP-2 & $\begin{array}{c}\text { norm. vs. GBM } \\
\text { norm. vs. met } \\
\text { GBM vs. met }\end{array}$ & $\begin{array}{l}\uparrow \\
\uparrow \\
\downarrow\end{array}$ & $\begin{array}{c}\text { mRNA: } * * * \text {, protein: } * * \\
\text { not significant } \\
\text { mRNA: } *\end{array}$ \\
\hline MMP-9 & $\begin{array}{l}\text { norm. vs. GBM } \\
\text { GBM vs. met. }\end{array}$ & $\begin{array}{l}\uparrow \\
\downarrow\end{array}$ & $\begin{array}{c}\text { mRNA: } * * * \text {, protein: } * * \\
\text { protein: } * *\end{array}$ \\
\hline neurocan & $\begin{array}{l}\text { norm. vs. met. } \\
\text { GBM vs. met. }\end{array}$ & $\downarrow$ & $\begin{array}{c}\text { mRNA: } * * \\
\text { mRNA: } * \text {, protein: } * *\end{array}$ \\
\hline tenascin- $\mathrm{R}$ & $\begin{array}{c}\text { norm. vs. GBM } \\
\text { norm. vs. met }\end{array}$ & $\downarrow$ & $\begin{array}{l}\text { mRNA: } * * * \\
\text { mRNA: } * * *\end{array}$ \\
\hline versican & norm. vs. GBM & $\uparrow$ & not significant \\
\hline
\end{tabular}

The arrows indicate the direction of change in the second group in the comparison compared to the first group. Stars indicate the degree of significance: $* \mathrm{p} \leq 0.05, * * \mathrm{p} \leq 0.01, * * * \mathrm{p} \leq 0.001, * * * * \mathrm{p} \leq 0.0001$.

their protein expression. The LogitBoost identified samples with an $84.7 \%$ probability using the following molecules: Erb-B1, Erb-B3, integrin- $\alpha 2,-\alpha 3$, integrin- $\beta 1$, laminin- $\alpha 1$, $-\alpha 4, M M P-2$ and $M M P-9$ and tenascin- $R$. It is important to note that when using integrin- $\alpha 2$ and laminin- $\alpha 4$ expression levels, the LogitBoost model performed with a $75 \%$ accuracy, suggesting the importance of these proteins. We managed to reach an $84.7 \%$ probability by adding molecules one by one until reaching the highest probability.

\section{Discussion}

Glioblastoma, the most common form of primary malignant brain cancer, is a devastating disease. Patients undergo surgery if possible, irradiation and chemotherapy. Tumors often recur and the quality of life decreases greatly $(2,3)$. The tumor cells not only show chemo- and radioinsensivity but they tend to invade the neighboring brain tissue as well (11). This prevents complete surgical resection and thus tumor recurrence seems inevitable. Despite being highly invasive locally, glioblastoma almost never metastasizes extracranially $(11,20)$. Secondary brain tumors (e.g. nonsmall cell lung cancer brain metastases), however, despite being malignant and being able to invade blood and lymphatic vessels, show no local invasiveness. They present as a well-demarcated lesions in the brain which are routinely removed (12).

Our research aimed to identify the molecular background of the differences between the infiltrative capacities of glioblastoma and NSCLC brain metastasis. Therefore, invasion-related ECM molecules were studied using QRTPCR and mass-spectrometry techniques. Remarkable differences were detected in the expression patterns of the histopathological groups. Certain molecules were identified as having a key role in tumor invasion by linear discriminant analysis, as differences in these components contributed to the identification of the histopathological group based upon the molecular composition of tumors. Our findings not only confirm previous data but new findings extend our understanding of glioma invasion.

The ECM in the brain consists of a large space filling glucose-amino-glycans like hyaluronan (HA) which is the major component of brain ECM. It binds to the receptors CD44 and HMMR (CD168). In our research, it was found that both of these HA receptors were significantly increased in GBM compared to normal tissue. Hyaluronan synthase 2 enzyme, responsible for HA synthesis, was also increased in GBM compared to normal brain. This indicates the role of HA in tumor migration and corresponds to literature data $(21,22)$. Protein-bound carbohydrates (glycoproteins) are also major components of the ECM, this groups includes many chondroitin sulfate proteoglycans (CSPGs) and heparan sulfate proteoglycans (HSPGs), including brevican, tenascins, syndecans and others. In GBM many of these proteoglycans were increased both compared to normal brain and metastasis, confirming their role in tumor invasiveness. Brevican, perlecan and syndecan-3 mRNA was significantly higher in GBM samples, these findings are similar to previously published data (23-27). Syndecan-4 levels were the highest in metastatic brain disease, and it confirms findings as syndecan-4 levels correlate with the metastatic potential of various tumor types $(28,29)$. Fibrous proteins are, however, present in a much smaller amount in the normal brain compared to the ECM in other body parts, normally they are mostly present in the perivascular ECM. Collagens, laminin and fibronectin are the most important representatives of fibrous proteins in the brain ECM (30, 31). During the analysis, a strong increase in various types of collagen fibers was detected in GBM and metastasis, compared to normal brain. Laminins were also increased. 


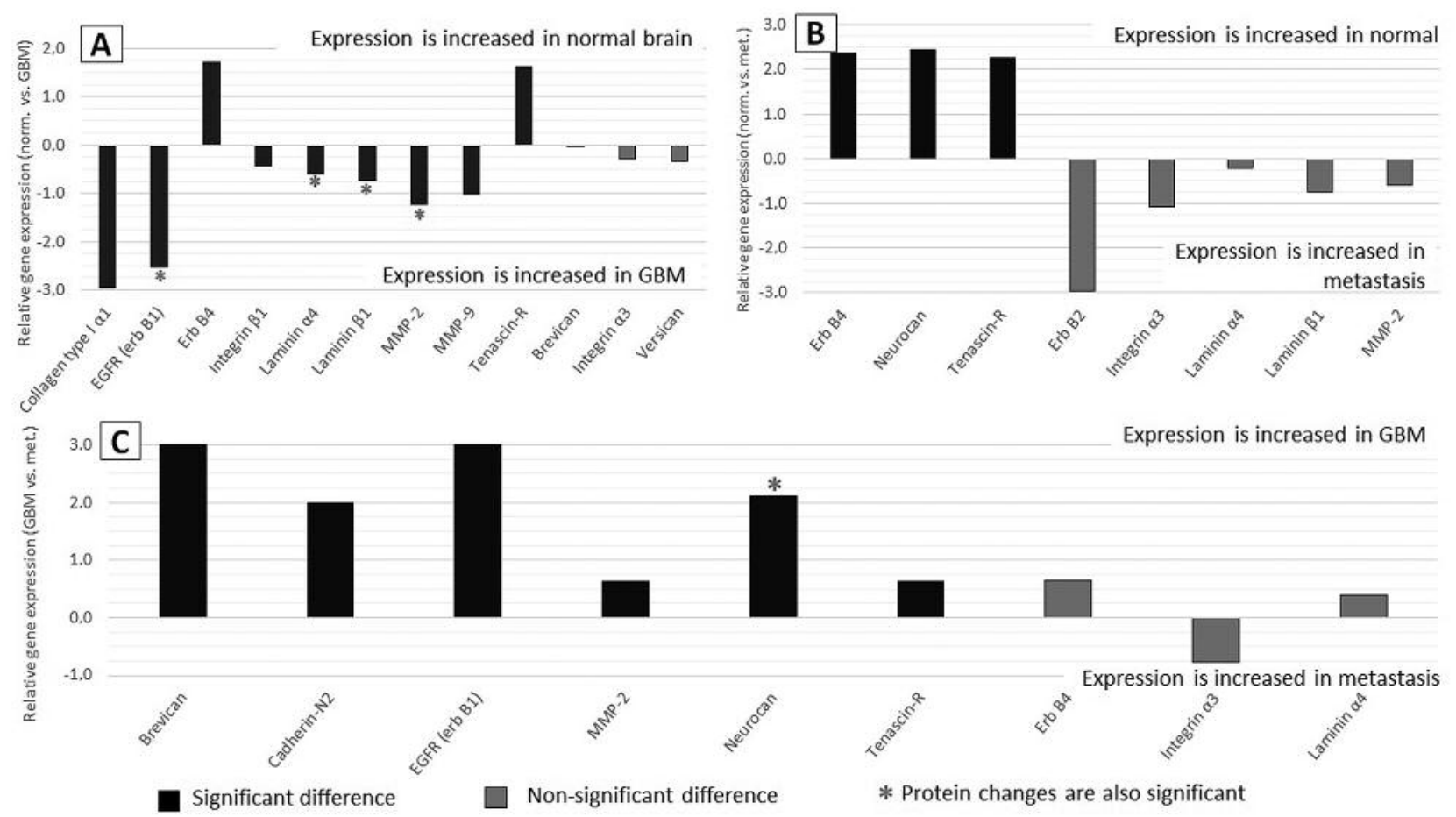

Figure 3. Concordant changes in mRNA and protein level in the comparison of (A) normal brain and glioblastoma, (B) normal brain and metastasis and $(C)$ glioblastoma and metastasis. Dark bars indicate significant mRNA difference, light bars indicate non-significant, but concordant mRNA changes. Asterisks indicate that both mRNA and protein changes are significant.

Fibrous network in the brain provides a track-like mechanism for glioma invasion, thus facilitating the migration of GBM cells (32-35). Integrins are important in tumor invasion, and in our study we were able to confirm an increased expression of $\alpha 9 \beta 1$ integrin in glioblastoma and an increase in $\beta 5$ integrins in metastatic brain tumors (36-38). Matrix remodeling is an important aspect of tumor cell invasion, and matrix metalloproteinases were increased in GBM samples, further confirming their role in invasion $(15,39,40)$.

Our research identified ECM components playing an important role in the invasion of cancer cells. By comparing normal, glioblastoma and metastatic tumor tissues we could identify major differences in the expression pattern of these groups, especially those that separate primary and secondary brain tumors. Concordant mRNA and protein expression data from human samples (instead of cell lines) underlines the significance of the findings and calls for further research in the topic. Understanding the steps and factors in glioma invasion is crucial for developing anti-invasive targeted oncotherapy and it seems that without this type of therapy we cannot expect any changes in patient outcome for GBM patients.

\section{Conflicts of Interest}

The Authors declare no conflict of interest.

\section{Acknowledgements}

This study was supported by the Hungarian Brain Research Program - Grant No. KTIA_13_NAP-A-V/3, II/7. and A. Klekner by the János Bolyai Scholarship of the Hungarian Academy of Sciences. Supported by the ÚNKP-16-3-I and ÚNKP-16-2-I New National Excellence Program of the Ministry of Human Capacities.

\section{References}

1 Ostrom QT, Gittleman H, Liao P, Rouse C, Chen Y, Dowling J, Wolinsky Y, Kruchko C and Barnholtz-Sloan J: CBTRUS Statistical Report: Primary brain and central nervous system tumors diagnosed in the United States in 2007-2011. NeuroOncology 16: iv1-iv63, 2014.

2 Louis DN, Perry A, Reifenberger G, von Deimling A, FigarellaBranger D, Cavenee WK, Ohgaki H, Wiestler OD, Kleihues P and Ellison DW: The 2016 World Health Organization classification of tumors of the central nervous system: a summary. Acta Neuropathol 131: 803-820, 2016. 
3 Urbańska K, Sokołowska J, Szmidt M and Sysa P: Glioblastoma multiforme - an overview. Contemp Oncol 18: 307-312, 2014.

4 Helseth R, Helseth E, Johannesen TB, Langberg CW, Lote K, Rønning P, Scheie D, Vik A and Meling TR: Overall survival, prognostic factors, and repeated surgery in a consecutive series of 516 patients with glioblastoma multiforme. Acta Neurol Scand 122: 159-167, 2010.

5 Nayak L, Lee EQ and Wen PY: Epidemiology of brain metastases. Curr Oncol Rep 14: 48-54, 2012.

6 Goldbrunner RH, Bernstein JJ and Tonn JC: Cell-extracellular matrix interaction in glioma invasion. Acta Neurochir (Wien) 141: 295-305, 1999.

7 Klekner A, Virga J, Toth J, Hortobagyi T, Der A, Szemcsak C and Bognar L: [The role of extracellular matrix components in the invasion of intracranial malignancies]. Magy Onkol 57: 222231, 2013.

8 Rutka JT, Apodaca G, Stern R and Rosenblum M: The extracellular matrix of the central and peripheral nervous systems: structure and function. J Neurosurg 69: 155-170, 1988.

9 Bellail AC, Hunter SB, Brat DJ, Tan C and Van Meir EG: Microregional extracellular matrix heterogeneity in brain modulates glioma cell invasion. Int J Biochem Cell Biol 36: 1046-1069, 2004.

10 Langley RR and Fidler IJ: The seed and soil hypothesis revisited-The role of tumor-stroma interactions in metastasis to different organs. Int J Cancer 128: 2527-2535, 2011.

11 Johnson DR and Galanis E: Medical management of high-grade astrocytoma: current and emerging therapies. Semin Oncol 41: 511-522, 2014.

12 Lo CK, Yu CH, Ma CC, Ko KM and Leung SCL: Surgical management of primary non-small-cell carcinoma of lung with synchronous solitary brain metastasis: Local experience. Hong Kong Med J 16: 186-191, 2010.

13 Olczyk P, Mencner $Ł$ and Komosinska-Vassev K: The role of the extracellular matrix components in cutaneous wound healing. Biomed Res Int 2014: 747584, 2014.

14 Petrás M, Hutóczki G, Varga I, Vereb G, Szöllősi J, Bognár L, Ruszthi P, Kenyeres A, Tóth J, Hanzély Z, Scholtz B and Klekner Á: Expression pattern of invasion-related molecules in cerebral tumors of different origin. Magy Onkológia 53: 253 $258,2009$.

15 Varga I, Hutóczki G, Petrás M, Scholtz B, Mikó E, Kenyeres A, Tóth J, Zahuczky G, Bognár L, Hanzély Z and Klekner A: Expression of invasion-related extracellular matrix molecules in human glioblastoma versus intracerebral lung adenocarcinoma metastasis. Zentralbl Neurochir 71: 173-180, 2010.

16 Livak KJ and Schmittgen TD: Analysis of relative gene expression data using real-time quantitative PCR and the 2(Delta Delta C(T)) Method. Methods 25: 402-408, 2001.

17 Bradford M: Rapid and Sensitive Method for Quantification of Microgram Quantities of Protein utilizing principle of ProteinDye-Binding. Anal Biochem 72: 248-254, 1976.

18 James A and Jorgensen C: Basic design of MRM assays for peptide quantification. Methods Mol Biol 658: 167-185, 2010.

19 Lange V, Picotti P, Domon B and Aebersold R: Selected reaction monitoring for quantitative proteomics: a tutorial. Mol Syst Biol 4: 222, 2008.

20 Sanai N and Berger MS: Glioma extent of resection and its impact on patient outcome. Neurosurgery 62: 753-764, 2008.
21 Zoltan-Jones A, Huang L, Ghatak S and Toole BP: Elevated Hyaluronan Production Induces Mesenchymal and Transformed Properties in Epithelial Cells. J Biol Chem 278: 45801-45810, 2003.

22 Akiyama Y, Jung S, Salhia B, Lee S, Hubbard S, Taylor M, Mainprize T, Akaishi K, van Furth W and Rutka JT: Hyaluronate receptors mediating glioma cell migration and proliferation. $\mathrm{J}$ Neurooncol 53: 115-127, 2001.

23 Viapiano MS, Hockfield S and Matthews RT: BEHAB/brevican requires ADAMTS-mediated proteolytic cleavage to promote glioma invasion. J Neurooncol 88: 261-272, 2008.

24 Nackaerts K, Verbeken E, Deneffe G, Vanderschueren B, Demedts $\mathrm{M}$ and David G: Heparan sulfate proteoglycan expression in human lung-cancer cells. Int J Cancer 74: 335-345, 1997.

25 Watanabe A, Mabuchi T, Satoh E, Furuya K, Zhang L, Maeda S and Naganuma H: Expression of syndecans, a heparan sulfate proteoglycan, in malignant gliomas: participation of nuclear factor-kappaB in up-regulation of syndecan-1 expression. $\mathbf{J}$ Neurooncol 77: 25-32, 2006.

26 Xian X, Gopal S and Couchman JR: Syndecans as receptors and organizers of the extracellular matrix. Cell Tissue Res 339: 3146, 2010.

27 Viapiano MS and Matthews RT: From barriers to bridges: chondroitin sulfate proteoglycans in neuropathology. Trends Mol Med 12: 488-496, 2006.

28 Vuoriluoto $\mathrm{K}$, Högnäs $\mathrm{G}$, Meller $\mathrm{P}$, Lehti $\mathrm{K}$ and Ivaska J: Syndecan-1 and -4 differentially regulate oncogenic K-ras dependent cell invasion into collagen through $\alpha 2 \beta 1$ integrin and MT1-MMP. Matrix Biol 30: 207-217, 2011.

29 Charni F, Friand V, Haddad O, Hlawaty H, Martin L, Vassy R, Oudar O, Gattegno L, Charnaux N and Sutton A: Syndecan-1 and syndecan-4 are involved in RANTES/CCL5-induced migration and invasion of human hepatoma cells. Biochim Biophys Acta - Gen Subj 1790: 1314-1326, 2009.

30 Wiranowska M, Ladd S, Smith SR and Gottschall PE: CD44 adhesion molecule and neuro-glial proteoglycan NG2 as invasive markers of glioma. Brain Cell Biol 35: 159-172, 2006.

31 Novak U and Kaye AH: Extracellular matrix and the brain: components and function. J Clin Neurosci 7: 280-290, 2000.

32 Tews DS: Adhesive and invasive features in gliomas. Pathol Res Pr 196: 701-711, 2000.

33 Ljubimova JY, Lakhter AJ, Loksh A, Yong WH, Riedinger MS, Miner JH, Sorokin LM, Ljubimov AV and Black KL: Overexpression of $\alpha 4$ chain-containing laminins in human glial tumors identified by gene microarray analysis. Cancer Res 61 : 5601-5610, 2001.

34 Kawataki T, Yamane T, Naganuma H, Rousselle P, Andurén I, Tryggvason $\mathrm{K}$ and Patarroyo M: Laminin isoforms and their integrin receptors in glioma cell migration and invasiveness: Evidence for a role of alpha5-laminin(s) and alpha3beta1 integrin. Exp Cell Res 313: 3819-3831, 2007.

35 Giese A, Rief MD, Loo MA and Berens ME: Determinants of human astrocytoma migration. Cancer Res 54: 3897-3904, 1994.

36 Guo W and Giancotti FG: Integrin signalling during tumour progression. Nat Rev Mol Cell Biol 5: 816-826, 2004.

37 Mahesparan R, Read T-A, Lund-Johansen M, Skaftnesmo KO, Bjerkvig $\mathrm{R}$ and Engebraaten O: Expression of extracellular matrix components in a highly infiltrative in vivo glioma model. Acta Neuropathol 105: 49-57, 2003. 
38 Abdollahi A, Griggs DW, Zieher H, Roth A, Lipson KE, Saffrich R, Gröne H-J, Hallahan DE, Reisfeld RA, Debus J, Niethammer AG and Huber PE: Inhibition of alpha(v)beta3 integrin survival signaling enhances antiangiogenic and antitumor effects of radiotherapy. Clin Cancer Res 11: 6270-6279, 2005.

39 Egeblad $M$ and Werb Z: New functions for the matrix metalloproteinases in cancer progression. Nat Rev Cancer 2: 161-174, 2002.
40 Rubenstein BM and Kaufman LJ: The role of extracellular matrix in glioma invasion: a cellular Potts model approach. Biophys J 95: 5661-5680, 2008.

Received June 6, 2017

Revised June 27, 2017

Accepted June 28, 2017 